\title{
Pengaruh Imagery Training Terhadap Kemampuan Renang Gaya Bebas Atlet Perempuan Klub Tirta Cempaka Kota Bengkulu
}

\section{The Influence of Imagery Training on The Freestyle Swimming Ability of Female Athletes at Tirta Cempaka Club Bengkulu City}

\author{
April Yanti Dwi Putri $^{1}$, Septian Raibowo ${ }^{2}$, Yahya Eko Nopiyanto ${ }^{3}$ \\ ${ }^{123}$ Pendidikan Jasmani, Universitas Bengkulu, Jl. WR Supratman Kandang Limun, \\ Bengkulu, 3871A, Indonesia
}

\begin{abstract}
Abstrak
Penelitian ini mempunyai tujuan untuk mengetahui adanya pengaruh imagery training terhadap kemampuan renang gaya bebas atlet Klub Tirta Cempaka Kota Bengkulu. Metode yang digunakan pada penelitian ini eksperimen semu dengan menggunakan teknik pengumpulan data pre-test and post-test one grup design. Populasi dalam penelitian ini berjumlah 20 atlet. Teknik pengambilan sampel menggunakan teknik sampling total. Maka sampel dalam penelitian ini adalah seluruh atlet perempuan berjumlah 20 atlet. Analisis data pada penelitian ini menggunakan uji-t untuk menguji hipotesis yang telah ditentukan. Uji syarat statistik di dapat hasil bahwa terdapatperangruh imagery training terhadap kemampuan renang gaya bebas. Dari data tersebut diketahui thitung 5.206 > t tabel 1.685 dengan signifikan 0.05 dan peningakatan persentase pengaruh imagery training terhadap kemampuan renang gaya bebas atlet perempuan klub tirta cempaka kota Bengkulu sebesar $77 \%$. Dengan demikian $\mathrm{Ha}$ diterima yaitu terdapat pengaruh imagery training terhadap kemampuan renang gaya bebas atlet putri Klub Tirta Cempaka Kota Bengkulu.
\end{abstract}

Kata kunci: Gaya Bebas, Imagery Training, Renang

\section{Abstract}

This study aims to determine the effect of imagery training on the freestyle swimming ability of the Tirta Cempaka Club athletes in Bengkulu City. The method used in this research is quasi-experimental by using data collection techniques pre-test and post-test one group design. The population in this study amounted to 20 athletes. The sampling technique used a total sampling technique. So the sample in this study were all female athletes totaling 20 athletes. The data analysis in this study used the t test to test the predetermined hypotheses. The statistical requirement test shows that there is a influence on imagery training on freestyle swimming ability. From these data, it is known that $t$ count 5.206> t table 1.685 with a significant 0.05 and an increase in the percentage of the influence of imagery training on the freestyle swimming ability of female athletes at Tirta Cempaka Club, Bengkulu City by 77\%. Thus, Ha is accepted, namely that there is an influence of imagery training on the freestyle swimming ability of the female athletes of the Tirta Cempaka Club, Bengkulu City.

Keywords: Freestyle, Imagery Training, Swimming 


\section{PENDAHULUAN}

Aktivitas fisik sistematis bertujuan untuk mendorong, memelihara kesehatan tubuh, dan memberikan dampak positif di tengah masyarakat merupakan kegiatan dari olahraga. Olahraga mempunyai peran penting dalam kehidupan, melalui olahraga banyak memberikan manfaat memiliki kepribadian yang baik, semangat yang tinggi, disiplin, jujur, kesehatan jasmani dan rohani dan mental yang tangguh yang akan membentuk atlet yang berkelas (Saputra \& Sutisyana, 2017). Olahraga memberikan semacam kebahagiaan yang dapat mempengaruhi psikologi seseorang. Dalam dunia olahraga terdapat beberapa cabang olahraga resmi yang disukai seluruh masyarakat di dunia, seperti: renang, basket, sepak bola, olahraga atletik, dll. Indonesia sendiri memiliki induk organisasi resmi salah satu cabang olahraganya adalah renang yaitu Persatuan Renang Seluruh Indonesia (PRSI).

Kegiatan yang dilakukan di dalam air bermacam gaya dan bentuk yang dapat memberikan manfaat kepada manusia merupakan kegiatan berenang (Neri et al., 2018). Manfaat berenang antara lain menjaga kesehatan tubuh, menambah dan meningkatkan serta menjaga kebugaran tubuh, keselamatan diri, untuk menumbuhkan aktifitas jasmani seperti endurance, power otot serta bermanfaat pula bagi pertumbuhan dan perkembangan jasmani anak, serta digunakan dalam media pendidikan, prestasi, pemulihan, dan rekreasi. Seperti yang tercantum dalam Undang-undang Sistem Keolahragaan Nasional Nomor 3 Tahun 2005 pada BAB VI Pasal 17 yang berbunyi: Ruang lingkup olahraga meliputi kegiatan 1. Olahraga pendidikan. 2. Olahraga rekreasi. 3. Olahraga prestasi (Sistem Keolahragaan Nasional, 2005).

Olahraga renang terdapat 4 gaya yaitu dada, punggung, bebas, dan kupukupu. Gaya bebas merupakan gaya yang paling cepat diantara 4 gaya tersebut (Neri et al., 2018). Faktor utama yang mempengaruhi gaya bebas ini adalah kecepatan. Semakin benar teknik yang yang dilakukan perenang saat berenang maka, semakin cepat perenang itu mencapai garis finish. Kesuksesan seorang perenang untuk menggapai prestasi tidak terlepas dari situasi mental atlet itu sendiri, sebab mental juga bagian penting didalam olahraga dan setiap cabang olahraga (Nopiyanto \& Dimyati, 2018). Latihan yang perlu diperhatikan setiap 
atlet meliputi taktik, fisik, dan teknik, namun dalam dunia olahraga juga perlu atlet perhatikan yaitu latihan mental (Jatra \& Raibowo, 2021; Wibowo \& Rahayu, 2016)(Wibowo \& Rahayu, 2016).

Imagery merupakan teknik atau metode untuk melatih kemampuan mental yang harus dikuasai atlet (Tangkudung \& Mylsidayu, 2017). Fakta membuktikan bahwa pola latihan imagery dapat memberikan manfaat untuk membentuk kembali pengalaman olahraga otak bagi para atlet (Komarudin, 2014). Sehingga atlet dapat menampilkan pola olahraga tersebut dengan benar dan tidak menutup kemungkinan latihan imagery dapat meningkatkan kecepatan atlet renang gaya bebas. Salah satunya adalah menguasai strategi yang digunakan dalam permainan, menguasai keterampilan olahraga, mempersiapkan diri untuk tampil percaya diri, mengontrol gejala psikologis, berkonsentrasi dan memperbaiki kesalahan serta atlet mampu memprediksi apa yang akan terjadi tidak lepas dari bantuan seorang pelatih.

Latihan mental imagery mengacu pada upaya dalam membentuk/ mengulang lagi pangalaman didalam otak, dengan membuat pangalaman dialam otak (Komarudin, 2014). Salah satunya adalah menguasai strategi yang digunakan dalam permainan, menguasai keterampilan olahraga, mempersiapkan diri untuk tampil percaya diri, mengontrol gejala psikologis, berkonsentrasi dan memperbaiki kesalahan serta atlet mampu memprediksi kedepannya (Firmansyah, 2011). Atlet harus mempunyai mental yang kuat, sehingga pada saat berlatih memiliki semangat yang tinggi, sepenuh hati, percaya diri yang kuat, pantang menyerah, dan tidak mudah terganggu yang disebabkan hal-hal personal (Raibowo et al., 2021). Setelah peneliti observasi di klub Tirta Cempaka Kota Bengkulu biasanya para atlet hanya diberikan latihan mental pada saat perlombaan saja. Penurunan tingkat prestasi pada atlet renang gaya bebas di klub Tirta Cempaka Kota Bengkulu meliputi banyak faktor seperti pencapaian best time yang tidak stabil, program latihan yang dilaksanakan tidak memenuhi target, strategi menurun, pengurangan atlet untuk mengikuti pertandingan, terutama dalam masalah mental seperti kepercayaan diri, kurangnya semangat yang tinggi, tidak bisa mengontrol tingkat kecemasan. Jika dilihat dari sudut pandang para atlet renang terutama pada klub Tirta Cempaka Kota Bengkulu kurangnya 
pemahaman tentang pentingnya latihan psikologi bagi mereka. Oleh karena itu, diperlukan evaluasi program yang ada di klub Tirta Cempaka. Karena dengan melakukan evaluasi mampu mengetahui suatu keberhasilan dari program yang telah dilaksanakan (Raibowo \& Nopiyanto, 2020). Bentuk evaluasi yang dilakukan oleh peneliti adalah dengan menerapkan latihan imagery.

Apabila atlet berhasil pada imagery training, tentu benar-benar percaya pada kemampuannya. Dari penelitian ini peneliti berkenan meneliti dan mengetahui bagimana pengaruh imagery tehadap renang gaya bebas klub Tirta Cempaka Kota Bengkulu. Penelitian ini dilakukan agar dapat mengetahui adanya pengaruh imagery training tarhadap kmampuan rengang gaya bebas atlet perempuan klub Tirta Cempaka Kota Bengkulu.

\section{METODE}

Jenis penelitian dalam penelitian ini yang digunakan yaitu kuantitatif, dengan menggunakan metode ekperimen. Metode yang dapat dibuat agar mengtahui adakah pengaruh pada perlakuan yang diberikan dalam situasi yang dapat teratasi merupakan pengertian dari metode penelitian eksperimen (Sugiyono, 2016).

Desain penelitian yaitu quasi eksperimen, bentuk desain quasi eksperimen menggunakan "Pre-test and Post-test One Group Design" menggunakan kelompok kontrol dan subjek.

Rancangan desain penelitian (Sugiono, 2011)

Keterangan:

$\mathrm{R}$ : Sampel

$\mathrm{O}_{1}$ : Prestest (sebelum diberi perlakuan)

$\mathrm{O}_{2}$ : Posttest (sesudah diberi perlakuan)

$\mathrm{X}$ : Treatment (imagery training)

Dari rancangan desain diatas dapat dijabarkan sebagai berikut, $\mathrm{R}$ ialah kelompok yang dipilih menjadi sampel, $\mathrm{O}_{1}$ ialah kemampuan awal siswa (prestest), kemudian $\mathrm{X}$ adalah perlakuan yang diberikan berupa imagery training, dan $\mathrm{O}_{2}$ kemampuan setelah diberikan perlakuan (posttest). 
Populasi pada penelitian ini 20 atlet perempuan klub Tirta Cempaka Kota Bengkulu. Teknik pengambilan sampel pada penelitian ini adalah sensus/sampling total. Teknik pengambilan sampel yang menggunakan seluruh anggota populasi lalu dijadikan sampel merupakan pengertian dari sensus atau sampling total (Sugiyono, 2018). Maka sampel yang digunakan adalah seluruh atlet perempuan klub Tirta Cempaka Kota Bengkulu.

Dalam penelitian ini ada dua jenis variabel meliputi variabel bebas (imagery training) dan variabel terikat (kemampuan renang gaya bebas 25 meter). Waktu yang dilakukan dalam penelitian ini selama tiga minggu, dilaksanakan 6x pertemuan dengan frekuensi 3x dalam 1 minggu dalam pemberian perlakuan imgery training (Pinandito, 2017). Pelaksaan penelitian ini diakukan di Kolam Hamtian Kota Bengkulu.

Teknik analisis data yang digunakan yaitu melihat hasil perbandingan hasil tes awal dan tes akhir kemampuan renang gaya bebas 25 meter dengan menggunakan uji t dan mengetahui kenaikan imagery training menggunakan deskriptif presentase, ekperimen penelitian ini dilakukan pada atlet perempuan klub Tirta Cempaka Kota Bengkulu. Teknik analisa data hasil yang digunakan yaitu uji normalitas, uji homogenitas, uji hipotesis, dan deskriptif presentase dengan mengunakan alat bantu hitung Microsoft Exel 2013.

Dilakukannya uji normalitas agar dapat mengetahui variabel yang ingin digunakan berdistribusi normal atau tidak, pada setiap skor dapat menggunakan rumus:

Sumber : (Pujianto, 2013)

Keterangan :

Xi: Data / Nilai

$X$ : Rata-rata (Mean)

S: Standar Deviasi

Jika diketahui data yang diteliti berdistribusi normal, kemudian data tersebut dapat dilanjutkan. Tahap selanjutnya yaitu menguji homogen, dapat menggunakan rumus: 
Sumber : (D. \& I. Pujianto, 2013)

Membandingkan kemampuan renang gaya bebas 25 meter pre-test dan posttest digunakannya analisa data atlet renang klub Tirta Cemapak Kota Bengkulu, analisis menggunakan uji-t.

$$
\mathrm{t}=\frac{\overline{x_{1}}-\overline{x_{2}}}{\sqrt{\frac{s_{1}^{2}}{n_{1}}+\frac{s_{2}^{2}}{n_{2}}-2 r\left(\frac{s_{1}}{\sqrt{n_{1}}}\right)\left(\frac{s_{2}}{\sqrt{n_{2}}}\right)}}
$$

Sumber : (D. \& I. Pujianto, 2013)

Keterangan:

$\overline{x_{1}}$ : rata-rata sampel 1

$\overline{x_{2}}$ : rata-rata sampel 2

$s_{1}$ : simpangan sampel 1

$s_{2}$ : simpangan baku sampel 2

$s_{1}^{2}$ : varians sampel 1

$s_{2}^{2}$ : varians sampel 2

$r$ : korelasi antara dua sampel

Membandingkan kemampuan renang gaya bebas 25 meter pre-test dan posttest digunkannya analisis data atlet renang club Tirta Cempaka Kota Bengkulu, analisis menggunakan uji-t. Data yang diuji berhubungan dengn hasil pada penelitian ini dan digunakan guna mengnalisis dengan lebih baik.

\section{HASIL}

Imagery training terhadap kemampuan renag gaya bebas sbelum diberikannya treatment kepada sempel, dilakukannya pre-test dan sesudah diberikan treatment sebanyak 6x pertemuan dilakukan (post-test). Untuk pre-test tedapat 20 sempel diraih 14.25 detik waktu terecpat dan 15.28 detik waktu terlama dngan rata-rata yang didapat 14.69 detik. Sesudah diberi treatment dengan menggunakan imagery training berupa program latihan. Setelahnya Dilakukan tes akhier didapatkan 13.16 detik waktu tercepat dan 14,88 detik wkatu terlama dengan nilai rata-rata didapatkan 14.21 detik. 
Tabel 1. Data hasil pre-test dan post-tes kemampuan renang gaya bebas 25 meter

\begin{tabular}{cccc}
\hline No & Nama & Pre-test & Post-test \\
\hline 1 & Arlin & 14.25 & 13.16 \\
2 & Adel & 14.29 & 13.19 \\
3 & Zizi & 14.32 & 13.21 \\
4 & Caca & 14.36 & 13.25 \\
5 & Putri Puspita & 14.59 & 13.29 \\
6 & Sabira & 14.61 & 14.07 \\
7 & Yosdita & 14.63 & 14.18 \\
8 & Fafa & 14.64 & 14.22 \\
9 & Bilqis & 14.66 & 14.3 \\
10 & Akila & 14.67 & 14.38 \\
11 & Rara & 14.69 & 14.47 \\
12 & Eka & 14.72 & 14.5 \\
13 & Cantika & 14.76 & 14.64 \\
14 & Manda & 14.78 & 14.67 \\
15 & Nadin & 14.8 & 14.69 \\
16 & Icha & 14.82 & 14.72 \\
17 & Yolanda & 14.85 & 14.77 \\
18 & Hawa & 15.01 & 14.8 \\
19 & Fadhila & 15.11 & 14.83 \\
\hline 20 & Wulan & 15.28 & 14.88 \\
\hline
\end{tabular}

\section{Pengujian Prasyarat Analisis}

Pengujian prasyarat analisis mencakup uji normlitas dan uji homogen. Hubungan dengan hasil penelitian pengujian data tersebut mempunyai tujuan agar dapat membantu menganalisis data dengan baik.

\section{Uji Normalitias}

Tabel 2. Hasil Uji Normalitas Sebaran Data

\begin{tabular}{cccccc}
\hline No & Variabel & N & Lo & Ltab & Distribusi \\
\hline 1 & Pre-test & 20 & 0.124 & 0.19 & Normal \\
2 & Post-test & 20 & 0.178 & 0.19 & Normal \\
\hline
\end{tabular}

\section{Uji Homogenitas}

Sampel disebut mempunyai varians homogenitas jika $\mathrm{F}_{\text {hitung }}<\mathrm{F}_{\text {tabel }}$ dengan bertaraf siginifikan 5\%.

Tabel 3. Hasil Uji Homogeinitas

\begin{tabular}{cccc}
\hline No & & Variabel 1 & Variabel 2 \\
\hline 1 & Mean & 14.69 & 14.21 \\
2 & Varians & 0.069 & 0.394 \\
3 & N & 20 & 20 \\
4 & Df/dk & 19 & 19 \\
5 & fh & 0.175 & \\
\hline 6 & Ft & 0.461 & \\
\hline
\end{tabular}




\section{Uji Hipotesis}

Rumus (uji paried t-test) diperoleh hasil analisia data seperti tabel dibawah:

Tabel 4. Hasil (Uji t)

\begin{tabular}{cccc}
\hline Dk=n1+n2-2 & Thitung & Ttabel $\boldsymbol{\alpha}=\mathbf{0 , 0 5}$ & Kesimpulan \\
38 & 5.206 & 1.685 & Signifikan
\end{tabular}

Dari hasil tersebut analisia uji-t tersebut mengemukakan adanya pengaruh imagery training terhadap kmampuan renang gaya bebas atlet perempuan klub Tirta Cempaka Kota Bengkulu yang dengan sampel 20 orang. Mendasari dari hasil analisia uji-t, diperolehnya $\mathbf{t}_{\mathbf{h}}=\mathbf{5 . 2 0 6}>\mathbf{t}_{\text {tabel }}=\mathbf{1 . 6 8 5}$ bertaraf signifikan $\alpha=$ 0,05 dan besarnya peningkatan imagery training tersebut dapat dilihat dari kenaikan presentasi $77 \%$.

\section{PEMBAHASAN}

Berdasarkan hasil tes kecepetan renang gaya bebas 25 meter atlet yaitu 14.67 detik. Setelah diberikannya treatment menggunakan imagery training selama 6x pertemuan dilakukannya tes diakhir menggunakannya istrumen yng sama pada tes diawal. Diperolehnya hasil tes dengan rata-rata kecepetan renang gaya bebas 25 meter atlet Klub tirta Cempaka Kota Bengkulu menjadi berubah menjadi 14.20 detik.

Hasil uji analisis data menunjukkan bahawa hipotesis (Ho) ditolak. Hal ini menunjukkan bahwa model imagery training memberikannya adanya pengaruh trhadap kmampuan renang gaya bebas yang didukung dengan data penelitian sebelumnya, terdapat pengaruh yang terbukti dari hasil penalitian berupa (posttest) kmampuan kecepetan renang gaya bebas 25 meter terjadi peningkatan dari (pre-test) stelah diberikan treatment berupa imagery training. Dapat disimpulkan imagery training berpengaruh terhadap kecepetan rengang gaya bebas 25 meter atlit Klub Tirta Cempaka Kota Bengkuku, dibuktikan setelah dilakukan uji t didaptkan hasil data dari $\mathrm{t}$ hitung $=5.206>\mathrm{t}$ tabel $=1.685$ dengan kenaikan presentase $77 \%$. Hal ini konsisten dengan teori para ahli bahwa imagery dapat meningkatkannya kmampuan psikologi bagi atlet diberikannya perlakuan 
(treatment) sejumlah 6 kali prtemuan dengan frekuensi 3x dalam 1 minggu (Pinandito, 2017).

Metode imagery training antara lain memiliki keunggulan, bentuk latihan kemampuan renang gaya bebas yang diberikan menyerupai dengan kondisi saat melakuakn renang gaya bebas yang sebernarnya. Imagery training adalah bagian tersruktur yang menyeluruh dalam latihan mental. Ketika atlet memvisualisaikan pada saat sedang latihan lalu membyangkan performa yang sempurna (Komarudin, 2014).

Diperkuat dengan pendapat ahli bahwa imagery training sangat berhasil dalam meningkatkan prestasi (Komarudin, 2014). Tujuan dilakukannya imagery training, berlatih berlajar keterampilan, mengambangkan setrategi, sebelum berkompetisi dapat mempersiapkan mental, mengembangkan keterampilan, mengatasi tekanan, cidera, latihan berat, dan gangguan-gangguan lainnya (Pinandito, 2017). Suatu prosedur intopeksi, yang mana seseorang dapat melihat, memikirkan, membayangkan, merasakan didalam fikiran dirinya sedang melakukan suatu pola gerakan dilakukan secara mengambil nafas dalam dengan menutup mata tanpa ada gerakan sebenarnya merupakan pengertian dari latihan imagery (Candra, 2016). Selain itu, latihan mental imagery merupakan bagian dari persiapan mental atlet (Nopiyanto, Dimyati, \& Dongoran, 2019).

Dari hasil penelitian dibuktikan sesudah dilakukannya uji t memperoleh hasil data thitung : $5.206>t$ tabel : 1.685 dengan kenaikan presentase $77 \%$ terjadi keinaikan yang signifikan imagery training berpengaruh terhadap kecepetan rengang gaya bebas 25 meter atlit Klub Tirta Cempaka Kota Bengkulu. Berdsarkan pendapat-pendapat ahli dan hasil dari penelitian yang didapat dilapangan, disimpulkan bahwa imagery training memiliki pengaruh terhadap kemampuan renang gaya bebas, dengan menggunakan program latihan imagery internal dan eksternal memberi gambaran yang terperinci dan nyata sehingga dapat membantu atlit dalam meningkatkannya dorongan yang dapat menimbulkan imajinasi lebih nyata di dalam fikiran. Melakukan metode imagery trianing baik sebelum latihan maupun sesudah latihan. Terdapat banyak manfaat dalam metode ini bagi pemula, karena dapat memberikan dorongan yang dapat menimbulkan imajinasi dalam diri atlet tentang gambaran secara lebih jelas dan lebih terperinci. 


\section{KESIMPULAN}

Bersumber pada hasil analisia dan pembahasan diatas dengan uji hipotesa digunkannya rumus uji-t dengan menggunakan tarif signifikan $a=0.05$ (Ho) ditolak dan terdapat peningkatan 77\%. Dapat disimpulkannya bahwa terdapat pengaruh imagery training terhadap kmampuan rengang gaya bebas atlit perempuan Klub Tirta Cempaka Kota Bengkulu. Dengan demikian bahwa imagery training dapat meningkatkan mental dan kemampuan rengang gaya bebas atlit perempuan Klub Tirta Cempaka Kota Bengkulu.

\section{REFERENSI}

Candra, A. (2016). View of Pengaruh Latihan Menendang Menggunakan Imageri Terhadap Akurasi Tendangan Ke Gawang. Jurnal Sport Area.

Firmansyah, H. (2011). Perbedaan Pengaruh Latihan Imagery dan Tanpa Latihan Imagery Terhadap Keterampilan Senam dan Kepercayaan Diri Atlet. JURNAL OLAHRAGA PRESTASI, 7(7), 1-10. https://doi.org/10.21831/jorpres.v7i7.10271

Jatra, R., \& Raibowo, S. (2021). Anxiety and Concentration of Tennis Athlete. Kinestetik: Jurnal Ilmiah Pendidikan Jasmani, 5(3), 580-589. https://doi.org/10.33369/jk.v5i3.17500

Komarudin. (2014). Psikologi Olahraga Latihan Keterampilan Mental Olahraga Kompetitif (Yusuf Hidayat (Ed.)). PT REMAJA ROSDAKARYA Bandung.

Neri, C. A., Sugiyanto, S., \& Sutisyana, A. (2018). Analisis Kelayakan Kola Renang. KINESTETIK, 2(1), 32-35. https://doi.org/10.33369/jk.v2i1.9184

Pinandito, laksi P. (2017). Pengaruh Latihan Mental Imagery Terhadap Peningkatan Ketepatan Smash Pada Atlet Bulutangkis Di PB Pratama Yogyakarta.

Pujianto, D. \& I. (2013). Bahan Ajar Dasar-dasar Penelitian Pendidikan Jasmani. Bengkulu: FKIP Universitas Bengkulu.

Pujianto, D., \& Insantio, B. (2013). Dasar - Dasar Penelitian Pendidikan Jasmani. FKIP Universitas Bengkulu.

Raibowo, S., Jatra, R., Prabowo, A., Nopiyanto, Y. E., \& Ilahi, B. R. (2021). Anxiety and Concentration of Tennis Chair Umpire. Halaman Olahraga Nusantara (Jurnal Ilmu Keolahragaan), 4(Ii), 271-281. https://doi.org/10.31851/hon.v4i25640

Raibowo, S., \& Nopiyanto, Y. E. (2020). Evaluasi Pembelajaran Pendidikan Jasmani Olahraga \& Kesehatan pada SMP Negeri Se-Kabupaten Mukomuko melalui Pendekatan Model Context, Input, Process \& Product ( CIPP ). Jurnal Pendidikan Kesehatan Rekreasi, 6(2), 146-165. https://doi.org/10.5281/zenodo.3881891

Saputra, H., \& Sutisyana, A. (2017). Pengaruh Lari Bolak-Balik Menggunakan Beban Kaki dan Circuit Training Terhadap Kemampuan Dribbling Pada Pemain Futsal Jugador Andalas Fc. KINESTETIK, 1(2), 131. 
https://doi.org/10.33369/jk.v1i2.3476

Sistem Keolahragaan Nasional. (2005). Undang-Undang Republik Indonesia.

Sugiono. (2011). Metode Penelitian Kuantitatif, Kulitatif, dan R\&D. PENERBIT ALFABETA BANDUNG.

Sugiyono. (2016). Metode Penelitian. Alfabeta.

Sugiyono. (2018). Metode Penelitian Kualitatif Kuantitatif dan $R \& D$ (Sutopo (Ed.); 1st ed.). PENERBIT ALFABETA BANDUNG.

Tangkudung \& Mylsidayu. (2017). Mental Training Aspek-Aspek Psikologi Dalam Olahraga (F. Kurniawan (Ed.); 1st ed.). Nivarna Bulak Kapal Blok A5 Jalam Mawar Putih RT.04 RW. 01 Aren Jaya, Bekasi Timur, Kota Bekasi 17111

Wibowo, S. A. P., \& Rahayu, N. I. (2016). Pengaruh Latihan Mental Imagery Terhadap Hasil Tembakan Atlet Menembak Rifle Jawa Barat. Jurnal Terapan Ilmu Keolahragaan, 23. https://doi.org/10.17509/jtikor.v1i2.2776 